\title{
SHEA/CDC/AHA Hospital Epidemiology Training Program
}

The SHEA/Centers for Disease Control (CDC) / American Hospital Association (AHA) Hospital Epidemiology Training Program will be held Illinois. The course is intended for infectious disease fellows and new hospital epidemiologists. It emphasizes hands-on exercises in which participants work in small groups to detect, investigate, and control epidemiological problems encountered in the hospital setting. These working sessions are supplemented with lectures and seminars covering fundamental aspects of hospital epidemiology. May 1619, 1991, in Chicago,

Information on scholarships for infectious disease fellows from Merck, Sharpe \& Dohme are included in this issue.

Drs. Donald Goldmann, William Mar-tone, and Robert Weinstein, and Gina Pugliese, $\mathrm{RN}, \mathrm{MS}$, will co-chair the program. Meeting, hotel, and travel arrangements will be available through the AHA. The registration fee for this program is $\$ 495$. The registration fee for infectious disease fellows is $\$ 250$ if the application is accompanied by proof of training status. For general registration information call the AHA (Phil Gordon): (312) 280-6764.

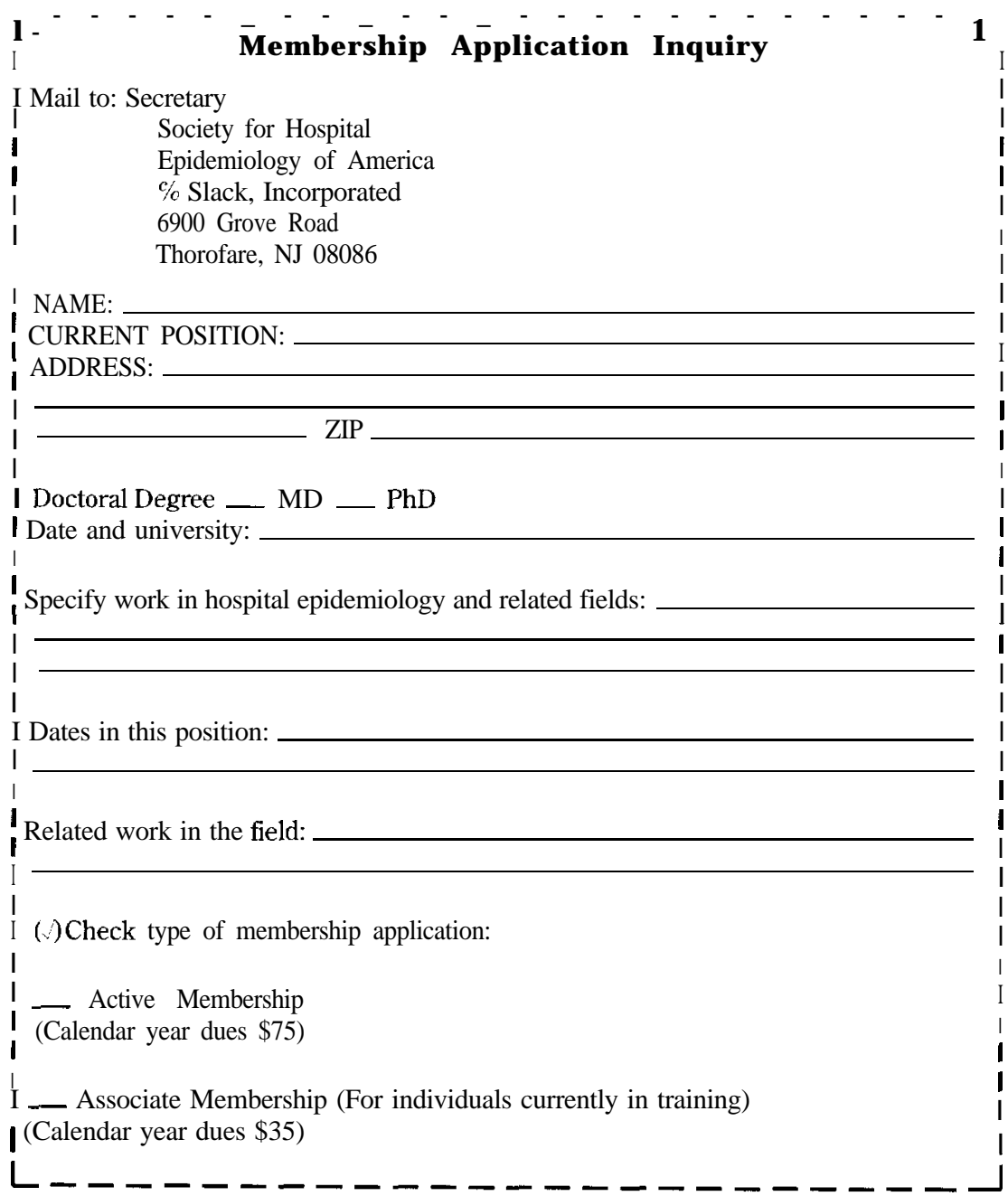

Coming Changes in the Newsletter

Starting within the next two to three months, the SHEA $N$ ewsletter will be mailed to all SHEA members as a freestanding publication. This will give room for advertising for positions, reporting changes in members' addresses and phone numbers, reporting minutes of board and committee meetings in more detail, and other items. If you have any material that you would like to see in the Newsletter, please write the Newsletter editor at the address shown below. Finally, please remember to renew your membership in SHEA.

\section{Reader's Suggestion}

One of our members, Dr. Ludwig A. Lettau, of Greenville, South Carolina, has written to suggest that we develop a SHEA motto to be used in conjunction with a logo. He notes that he has “... a sign in my hospital epidemiology office stating 'The Bug Stops Here,' which I am proposing as a potential motto for the organization. Maybe this could be translated into Latin..."

In fact, SHEA has a typemark, which is the stylized spelling of SHEA that appears on the cover of our directory. However, we have neither a true logo nor a motto. Members who wish to submit motto or logo suggestions should write to the address noted below.

Brief items of interest for the SHEA Newsletter may be sent to Robert A. Weinstein, MD, SHEA Newsletter Editor, Division of Infectious Diseases, Michael Reese Hospital, Lake Shore Drive at 31st St., Chicago, IL 60616. Copy must be typed, doublespaced and may not exceed five pages. 